\title{
Correction: Validation of Korean Version of Coma Recovery Scale-Revised (K-CRSR)
}

\author{
Hee Jun Han, $\mathrm{MD}^{1}$, Ee Jin Kim, $\mathrm{MD}^{1}$, Hae Jin Lee, $\mathrm{MD}^{1}$, Sung Bom Pyun, MD, PhD ${ }^{2}$, \\ Kyung Lim Joa, MD, $\mathrm{PhD}^{1}$, Han Young Jung, $\mathrm{MD}, \mathrm{PhD}^{1}$ \\ ${ }^{1}$ Department of Physical and Rehabilitation Medicine, Inha University College of Medicine, Incheon; \\ ${ }^{2}$ Department of Physical Medicine and Rehabilitation, Korea University Anam Hospital, Seoul, Korea
}

https://doi.org/10.5535/arm.2018.42.4.536

Ann Rehabil Med 2018;42(4):536-541

After publication of the article, we found that an in-text citation of supplementary data is missing. The correct sentence is as follows, with changes in bold font:

On page 537, a paragraph of "Translation" in Materials and Methods section

To translate the CRSR into K-CRSR, a Korean rehabilitation physician who was an expert in English was engaged with permission from Giacino, the author of the CRSR from Harvard Medical School. A draft of the K-CRSR was then backtranslated into English and verified by the author. After appropriate modifications, the final form of the K-CRSR was administered to patients (Supplement A).

@ This is an open-access article distributed under the terms of the Creative Commons Attribution Non-Commercial License (http://creativecommons.org/ licenses/by-nc/4.0) which permits unrestricted noncommercial use, distribution, and reproduction in any medium, provided the original work is properly cited. Copyright $\odot 2021$ by Korean Academy of Rehabilitation Medicine 